\title{
LONG-PERIOD SURFACE WAVES OF FOUR WESTERN UNITED STATES EARTHQUAKES RECORDED BY THE PASADENA STRAINMETER
}

\author{
By Diane I. Doser and Hiroo Kanamori
}

\begin{abstract}
Long-period surface waves recorded on the north-south Pasadena strainmeter are used to determine the seismic moments and fault parameters of the 19 May 1940 Imperial Valley, California, the 16 December 1954 Dixie Valley and Fairview Peak, Nevada, and the 18 August 1959 Hebgen Lake, Montana, earthquakes. Synthetic strain seismograms are matched with the observed strainmeter seismograms. Source parameters from the strainmeter modeling are more consistent with source parameters estimated from geodetic and geologic information than parameters estimated from short-period $(<15 \mathrm{sec})$ body wave data. Long-period surface wave moment estimates agree well with geodetic estimates of moment, but are 1.5 to 5 times greater than moments obtained from modeling of teleseismic body waves or geologic information. The Imperial Valley earthquake is best modeled as consisting of 5 point sources along a fault $87.5 \mathrm{~km}$ in length with a strike, rake, and dip of $326^{\circ}, 180^{\circ}$, and $90^{\circ}$. The moment for the earthquake was $4.8 \times 10^{19} \mathrm{~N}-\mathrm{m}$. The synthetic seismogram that best models the Fairview Peak and Dixie Valley earthquakes assumes that the Fairview Peak earthquake was twice the size of the Dixie Valley event. Moments of 5.9 to $13 \times 10^{19}$ and 3 to 6.5 $\times 10^{19} \mathrm{~N}$-m are obtained for these events. A moment of $1.5 \times 10^{20} \mathrm{~N}-\mathrm{m}$ is obtained for the Hebgen Lake earthquake. Love waves of this earthquake are best modeled by a fault striking $102^{\circ}$, although surface faulting produced during the earthquake strikes $130^{\circ}$.
\end{abstract}

\section{INTRODUCTION}

Long-period surface waves $(R 2, R 3, G 2$, and $G 3)$ for Western United States earthquakes with $6.8 \leqq M \leqq 7.5$ were often well-recorded by the long-period, lowgain Benioff strain seismometers operating at Pasadena from about 1935 to 1960. We have modeled the long-period waves for four earthquakes (Figure 1) occurring between 1940 and 1954. These earthquakes produced significant $(>2 \mathrm{~m})$ surface displacements, and the geodetic, seismic (first motions and body waves), and geologic data have been examined by other researchers. Although it is not possible to constrain the mechanism from the Pasadena seismograms alone, the amplitude of long-period waves provides a reliable estimate of the seismic moment if the source geometry is approximately known. In this paper, we compare the observed surface waves with synthetic seismograms computed for a suite of models. Because of the lateral heterogeneities of the earth, the details of the waveform cannot be compared. We will use primarily the gross amplitude to estimate the seismic moment.

For many of these earthquakes, the seismic moment has been estimated from body waves or geodetic data. Since the period of the body waves is usually shorter than $15 \mathrm{sec}$, the moment estimated from body waves may not represent the total seismic moment. The seismic moment estimated from geodetic data is subject to a large uncertainty because of the limited spatial coverage of the data. Since the period of the surface waves recorded by the Benioff strain seismometer (50 to 200 $\mathrm{sec}$ ) is longer than the source process time of these earthquakes, estimated to be 


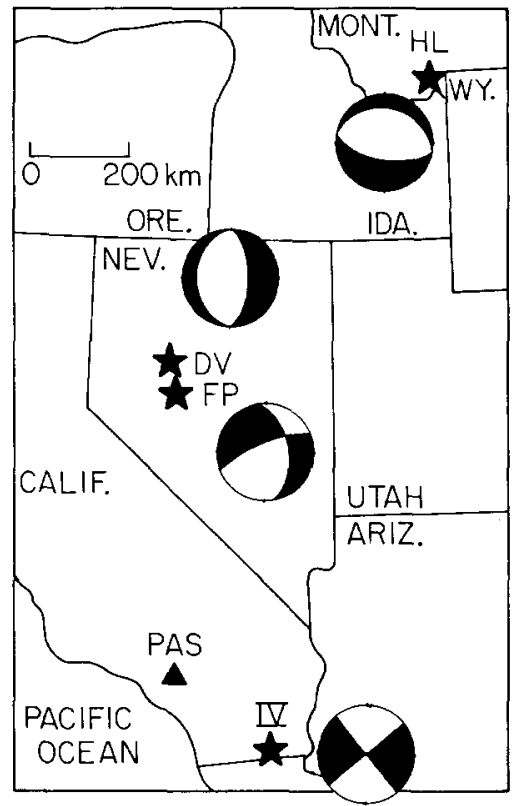

FIG. 1. Location of Pasadena strainmeter (triangle) and the four earthquakes (stars) discussed in this study. $\mathrm{HL}=$ Hebgen Lake, DV = Dixie Valley, FP = Fairview Peak, IV = Imperial Valley. Focal mechanisms shown are the mechanisms that best fit the observed strainmeter seismograms.

shorter than $20 \mathrm{sec}$, we hope that the moment obtained from the surface wave data will complement the results obtained by earlier studies.

\section{DATA ANALYSIS}

Seismograms for this study were recorded on a strainmeter consisting of a $20 \mathrm{~m}$ quartz rod and velocity transducer coupled to a galvanometer with a natural period of $70 \mathrm{sec}$ and damping constant of about 1 . Benioff (1935) has shown that the displacement response of this strainmeter system to an incident wave of constant phase velocity is the same as that of a mechanical pendulum seismograph with natural period and damping constant equal to those of the galvanometer. Figure 2a shows a strain seismogram (north-south component) recorded at Pasadena for the 1959 Hebgen Lake earthquake.

The magnification of the instrument varies between 1935 and 1960 , and was calculated by comparing strainmeter seismograms for $M>7 \frac{3}{4}$ earthquakes with those recorded by Wood Anderson $\left(T_{s}=0.8 \mathrm{sec}\right)$ and long-period Benioff $\left(T_{s}=1\right.$ sec, $T_{g}=90 \mathrm{sec}$ ) seismographs, the latter two instruments having magnifications that were better documented between 1935 and 1960. In 1940, the magnification for the north-south component was about 100 , and in 1954 and 1959 it was 360 . An east-west strainmeter was also in operation during this time period, but it either was not recording at the time of the earthquakes of this study or its orientation was nodal to the earthquakes.

Usually synthetic seismograms for this strainmeter are computed by convolving the displacement response of the strainmeter treated as an ordinary pendulum seismograph (e.g., Kanamori and Cipar, 1974). This method works well for a wave train arriving at a station from a certain azimuth. If the wave train comes from the opposite azimuth, the polarity should be reversed. Hence, if two wave trains such 


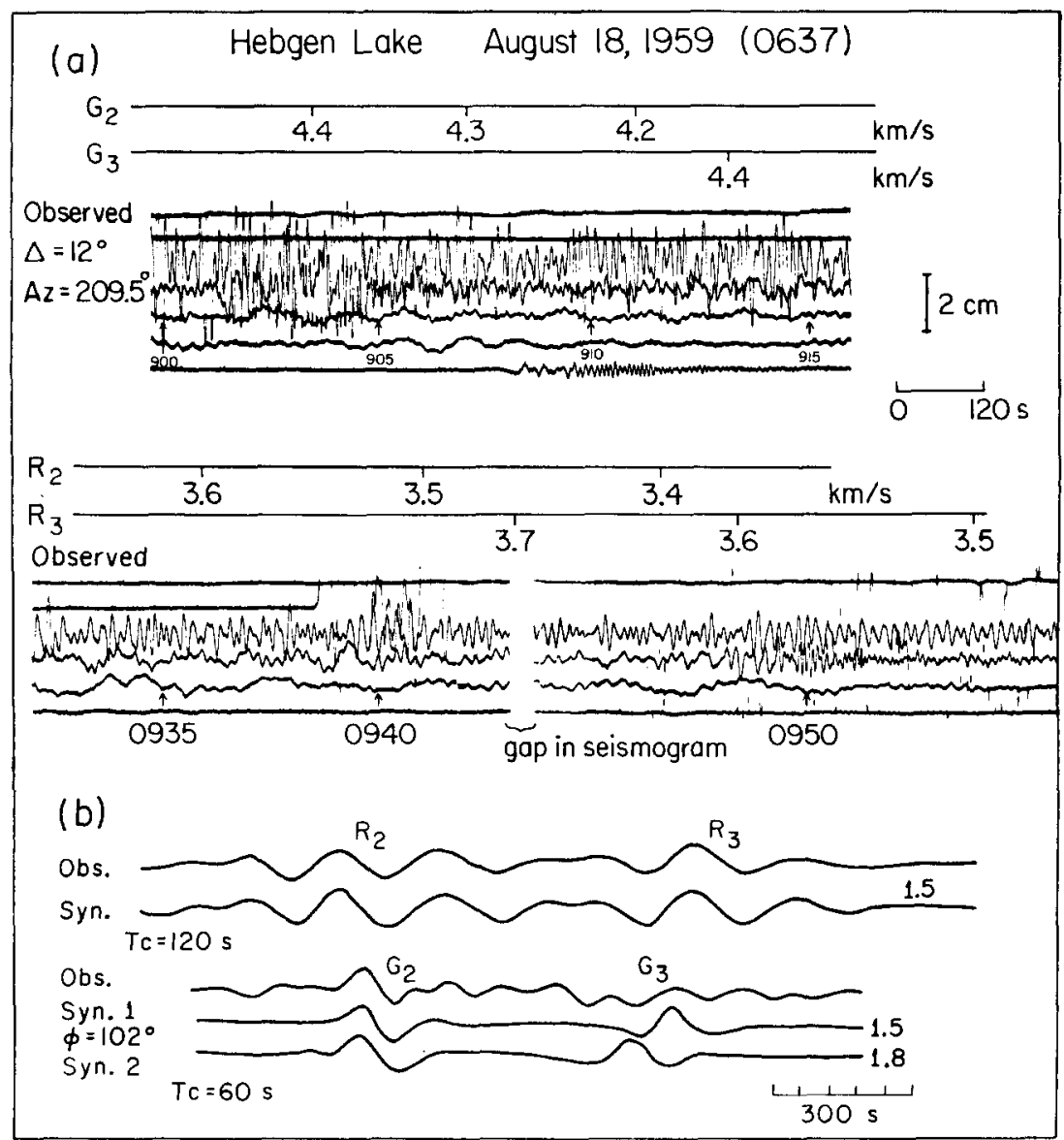

FIG. 2. (a) Observed seismograms for the Hebgen lake earthquake. The scales above the seismograms show the group velocities for $G 2$ and $G 3$ and $R 2$ and $R 3$. (b) Observed and synthetic seismograms for the Hebgen Lake earthquake, filtered with a low-pass filter. The synthetic seismograms were generated for a point source with the given fault parameters and normalized to the maximum amplitude of the observed seismogram. $\phi=$ strike. On all figures, the number to the right of each synthetic seismogram is the seismic moment $\times 10^{20} \mathrm{~N}$-m unless otherwise noted.

as $G 1$ and $G 2$ are arriving simultaneously from opposite azimuths, this method cannot be used. Conventional techniques for calculating synthetic seismograms fail because the Pasadena strainmeter is located at an epicentral distance of $\leqq 12^{\circ}$ for all the earthquakes studied in this paper, and the arrivals of the $G 2$ and $G 3$ (and also the $R 2$ and $R 3$ ) wave trains overlap. Furthermore, at this short distance range, Love and Rayleigh waves are not simple polarized waves; Love waves have significant radial component, and Rayleigh waves have large transverse component. As a consequence, the response of the strainmeter to the surface waves is very complex.

In order to circumvent these difficulties, we did not use the conventional method of computing strainmeter response from displacement records. Instead, we directly derived expressions for strain from Kanamori and Cipar's (1974) expressions for displacement and convolved the strains with the strain response of the Benioff instrument. The synthetic seismograms presented in this study are computed from strains using either fundamental torsional or spheroidal modes of order number 2 to 200 for the earth model 5.08 $M$ (Kanamori, 1970). For the Hebgen Lake, Fairview Peak, and Dixie Valley earthquakes, we assumed a focal depth of $16 \mathrm{~km}$ as suggested from the body wave modeling (Doser, 1985a, b). We assumed a shallower focal 
depth of $9.75 \mathrm{~km}$ for the Imperial Valley earthquake, since the maximum depth of seismicity in this region is 10 to $12 \mathrm{~km}$ (Doser and Kanamori, 1986).

\section{Fault Parameters and Seismic Moment}

Hegben Lake, Montana, 1959. The 1959 Hebgen Lake earthquake ( $\Delta=12^{\circ}$ from Pasadena) is the best studied earthquake of the four events we have modeled. Because Pasadena is at an azimuth of $210^{\circ}$ from this earthquake, the north-south strainmeter was favorably oriented to record both Love and Rayleigh waves from this event. [See Benioff (1935) for the directional response characteristics of the strainmeter to Love and Rayleigh waves.] Body wave analysis shows that the earthquake was a complex event with an $m_{b}=6.0$ event followed 5 sec later by an $M=7.1$ event (Doser, 1985a); however, the first event is too small to be distinguished on the strainmeter records. Doser (1985a) inverted first motion polarities and teleseismic body wave amplitudes to obtain a focal mechanism of strike $=100^{\circ}$, rake $=-90^{\circ}$, and dip $=60^{\circ}$ and a combined moment of $1 \times 10^{20} \mathrm{~N}-\mathrm{m}$ for the events. The focal mechanism agrees with Ryall's (1962) mechanism from first motion data and with Savage and Hastie's (1966) model based on geodetic data. The surface faulting had a strike and dip of $130^{\circ}$ and $70^{\circ}$ (Witkind, 1964). We computed synthetic seismograms using Ryall's parameters and compared them with the observed seismograms in Figure 2b. For this comparison, we filtered out shortperiod waves using a low-pass filter described in Kanamori and Stewart (1979). Cut-off periods of 60 and $120 \mathrm{sec}$ are used for the Love and Rayleigh waves, respectively. The synthetics are not sensitive to the length of faulting which was varied between 20 and $50 \mathrm{~km}$, using the correction for source finiteness introduced by Ben-Menahem (1961).

We also computed synthetics generated for strike and dip values that match the surface faulting. Although the synthetics for $R 2$ and $R 3$ are identical in shape, slight differences exist between the two synthetics for $G 2$ and $G 3$ as shown in Figure $2 \mathrm{~b}$. Therefore, it appears possible to differentiate between the two fault models based on the shape of the synthetics, with the $102^{\circ}$ strike, $-90^{\circ}$ rake, and $60^{\circ}$ dip model having a slightly better fit. This mechanism is shown in Figure 1.

A moment of $1.5 \times 10^{20} \mathrm{~N}$-m is obtained from both Rayleigh and Love waves using the $102^{\circ},-90^{\circ}$, and $60^{\circ}$ (strike, rake, and dip, respectively) model. This value is 50 per cent larger than the moment estimated from body wave modeling. A moment of $4.1 \times 10^{19} \mathrm{~N}$-m was estimated from geologic data (Doser, 1985a), a value nearly four times as small as the surface wave estimate. Savage and Hastie (1966) estimated a fault length of $30 \mathrm{~km}$, a fault width of $15 \mathrm{~km}$, and an average slip of 10 $\mathrm{m}$ for the earthquake from geodetic data. These estimates give a moment of $1.5 \times$ $10^{20} \mathrm{~N}$-m, a value in excellent agreement with the long period surface wave moment.

Dixie Valley and Fairview Peak, Nevada, 1954. The 1954 Fairview Peak $(M=$ 7.1) and Dixie Valley $(M=6.8)$ earthquakes are also complex earthquakes that exhibit teleseismic body waveforms best modeled by multiple source-time functions (Doser, 1985b). Romney (1957) obtained a focal mechanism of strike $=350^{\circ}$, rake $=-160^{\circ}$, and $\operatorname{dip}=50^{\circ}$ for the Fairview Peak earthquake, while Okaya and Thompson (1985) and Doser (1985b) obtained similar mechanisms from body wave modeling. Savage and Hastie (1969) obtained a fault model from geodetic data that matched the observed surface faulting with a strike and dip of $10^{\circ}$ and $57^{\circ}$.

The Dixie Valley earthquake occurred $4 \mathrm{~min}$ and $20 \mathrm{sec}$ after the Fairview Peak earthquake. Because of its proximity in time to the Fairview Peak earthquake, a focal mechanism cannot be determined from first motion data. The surface faulting 
has a strike of $0^{\circ}$ to $10^{\circ}$ and a dip of $55^{\circ}$ to $75^{\circ}$ (Slemmons, 1957). Doser (1985b) obtained a poorly constrained focal mechanism of $0^{\circ},-90^{\circ}$, and $60^{\circ}$ (strike, rake, and dip, respectively) from body wave modeling.

Geologic information (Slemmons, 1957) gives a moment of $4.8 \times 10^{19} \mathrm{~N}-\mathrm{m}(2.8$ $\mathrm{m}$ average slip, $30 \mathrm{~km}$ length, and $15 \mathrm{~km}$ depth) for the Fairview Peak earthquake and $2.3 \times 10^{19} \mathrm{~N}-\mathrm{m}$ for the Dixie Valley event $(1.8 \mathrm{~m}$ average slip, $22 \mathrm{~km}$ length, and $15 \mathrm{~km}$ depth). Savage and Hastie (1969) estimate a fault length of $50 \mathrm{~km}$, an average slip of $3.7 \mathrm{~m}(2.3 \mathrm{~m}$ vertical and $2.9 \mathrm{~m}$ horizontal $)$ and a fault width of 8 $\mathrm{km}$ for the Fairview Peak earthquake. This gives a moment of $4.9 \times 10^{19} \mathrm{~N}-\mathrm{m}$. Savage and Hastie noted that their estimate of fault width was probably somewhat less than the true width of the fault. Snay et al. (1985) have reexamined the geodetic data in the region and have constructed a complicated fault model to match the geodetic data. Their model predicts a combined moment of $1.5 \times 10^{20} \mathrm{~N}-\mathrm{m}$ for the Fairview Peak and Dixie Valley earthquakes. Doser (in preparation, 1986) has estimated body wave seismic moments of 3 to $5 \times 10^{19}$ and $1 \times 10^{19} \mathrm{~N}-\mathrm{m}$ for the Fairview Peak and Dixie Valley earthquakes, respectively.

Figure 3a shows the observed seismogram for the earthquake. Since the backazimuth at Pasadena is $0^{\circ}$, the north-south strainmeter did not record Love waves well. We therefore only model Rayleigh waves.

Figure 3, b and c, compares the observed seismogram with synthetics. Both the observed and synthetic seismograms are low-pass-filtered with a cut-off period of 100 sec. The first two synthetics (nos. 1 and 2) are obtained by modeling only the Fairview Peak event with the focal mechanism of Romney (1957) (no. 1) and with the mechanism (strike $=10^{\circ}$, rake $=-150^{\circ}$, and dip $=60^{\circ}$ ) that is consistent with the surface faulting and geodetic data (no. 2). Although the two synthetics are

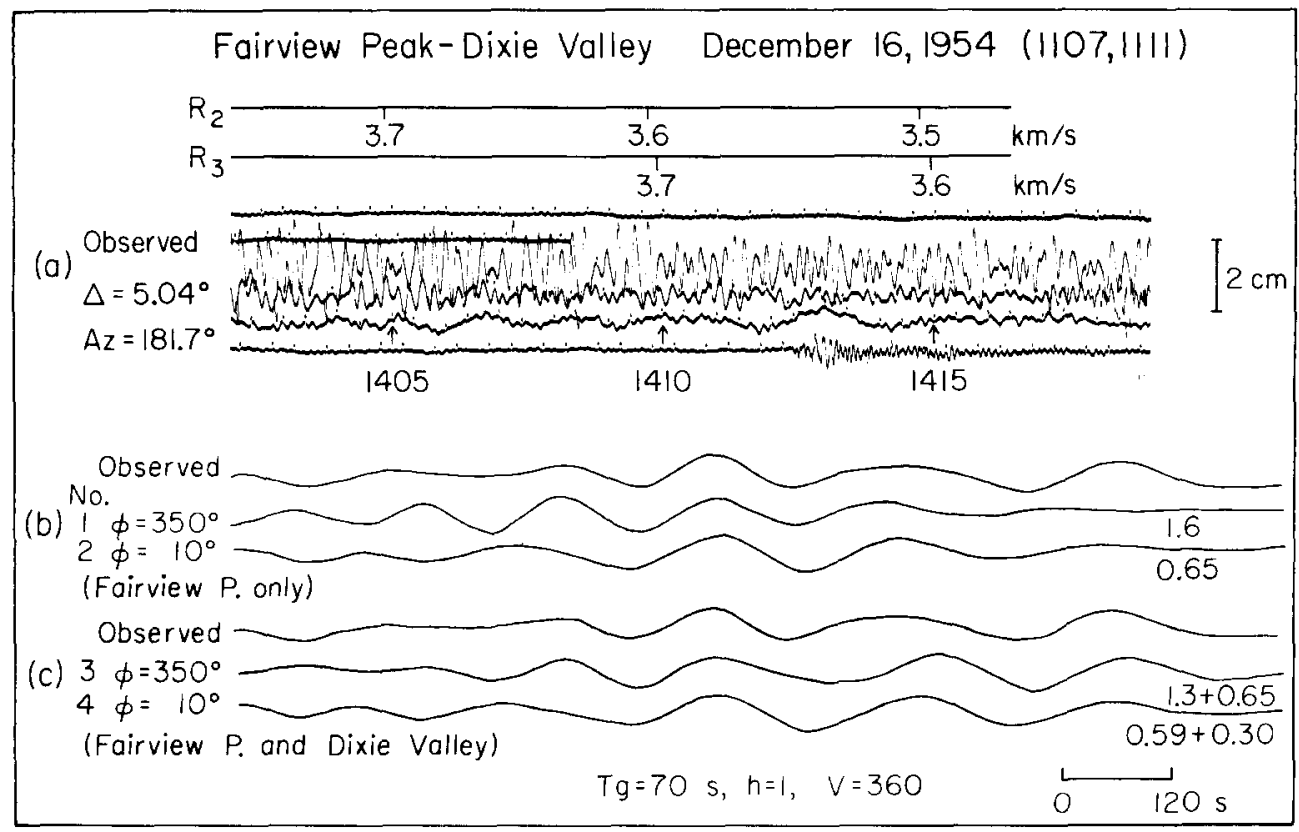

Fig. 3. (a) Observed seismograms for the Fairview Peak and Dixie Valley earthquakes. (b) Observed and synthetic seismograms for the Fairview Peak and Dixie Valley earthquakes, filtered with a low-pass filter. The synthetic seismograms model only the Fairview Peak earthquake with strike values of $350^{\circ}$ and $10^{\circ}$. (c) Synthetic seismograms that model both the Fairview Peak and Dixie Valley earthquakes with strike values of $350^{\circ}$ and $10^{\circ}$ for the Fairview Peak earthquake. The Dixie Valley event was modeled with a strike, rake, and dip of $0^{\circ},-90^{\circ}$, and $60^{\circ}$. 
similar at long-period, they are different at short-period. The second synthetic (strike $=10^{\circ}$ ) matches the data better. The observed seismogram exhibits a longperiod wave train at the end, which is probably excited by Dixie Valley earthquake. The synthetic seismograms are not sensitive to the length of faulting, at least over a range of 20 to $50 \mathrm{~km}$.

We then added a synthetic constructed for the Dixie Valley event with a focal mechanism of $0^{\circ},-90^{\circ}$, and $60^{\circ}$ (Figure $3 \mathrm{c}$, nos. 3 and 4). We assumed that the moment of the Dixie Valley earthquake is half that of the Fairview Peak earthquake since the Dixie Valley event was 0.2 magnitude units smaller and had about half the observed surface displacement of the Fairview Peak event along a fault of comparable length.

Both synthetics computed for the two models of the Fairview Peak earthquake match the observed record satisfactorily. For the model with Romney's mechanism (no. 3), the seismic moments are $1.3 \times 10^{20}$ and $6.5 \times 10^{19} \mathrm{~N}-\mathrm{m}$ for the Fairview Peak and Dixie Valley earthquakes, respectively. For the model with the fault strike of $10^{\circ}$ (no. 4), the corresponding moments are $5.9 \times 10^{19}$ and $3.0 \times 10^{19} \mathrm{~N}-\mathrm{m}$. Thus, we obtain a range of 1 to $2 \times 10^{20} \mathrm{~N}$-m for the combined moment of the Fairview Peak and Dixie Valley earthquake sequence. This range is more comparable to the geodetic estimate of moment and is 3 to 5 times larger than the body wave estimates.

Imperial Valley, California, 1940. For the 1940 Imperial Valley earthquake $(M=$ $6.7, \Delta=2.6^{\circ}$ ) the backazimuth at Pasadena is $123^{\circ}$, and the north-south strainmeter recorded only Love waves. A focal mechanism has not been determined from first motion data or teleseismic body wave modeling for this earthquake, so a synthetic seismogram for $G 2$ and $G 3$ (Figure 4) was generated using a strike, rake, and dip of $326^{\circ}, 180^{\circ}$, and $90^{\circ}$, values consistent with observed surface faulting (Sharp, 1982). Note that this seismogram has a magnification of 3.6 times smaller than seismograms shown previously.

Trifunac and Brune (1970) have studied the accelerograms recorded at El Centro for this earthquake and have concluded that the main shock sequence consisted of at least four subevents, with each succeeding event occurring southeast of the previous event. To determine whether the southeast direction of rupture propagation could be seen in the shape of the observed seismogram, we computed synthetic seismograms for a single point source and for 4 to 6 point sources. These synthetics are shown in Figure 4.

The point source synthetic shows distinct $G 2$ and $G 3$ phases with about the same amplitude. In contrast, the observed $G 2$ and $G 3$ are very different. $G 2$ is impulsive, and $G 3$ is smaller and longer period. This asymmetry can be explained by a finite source rupturing to the south. Since $G 2$ and $G 3$ are arriving together, the conventional directivity methods cannot be used. We therefore modeled the earthquake as a series of point sources, with each succeeding source to the southeast of the previous source. The synthetics shown in Figure 4 were computed for 4, 5, and 6 point sources, each $17.5 \mathrm{~km}$ apart in distance and $7 \mathrm{sec}$ apart in time. As the number of points increases (i.e., the fault length increases), the asymmetry increases. The best fit to the data is for the case with 5 point sources. In view of the poor signalto-noise ratio of the data, however, the models with 4 to 6 point sources are considered satisfactory. This range corresponds to a range of fault length from 70 to $105 \mathrm{~km}$ which is in reasonable agreement with the fault length inferred from other data (Richter, 1958; Trifunac and Brune, 1970).

The seismic moment for the 5-point source model is $4.8 \times 10^{19} \mathrm{~N}-\mathrm{m}$. A moment of $3.1 \times 10^{19} \mathrm{~N}-\mathrm{m}$ [1.2 m slip, $65 \mathrm{~km}$ fault length, and $12 \mathrm{~km}$ depth (Richter, 1958; Trifunac and Brune, 1970)] is estimated from the geologic information. Reilinger 


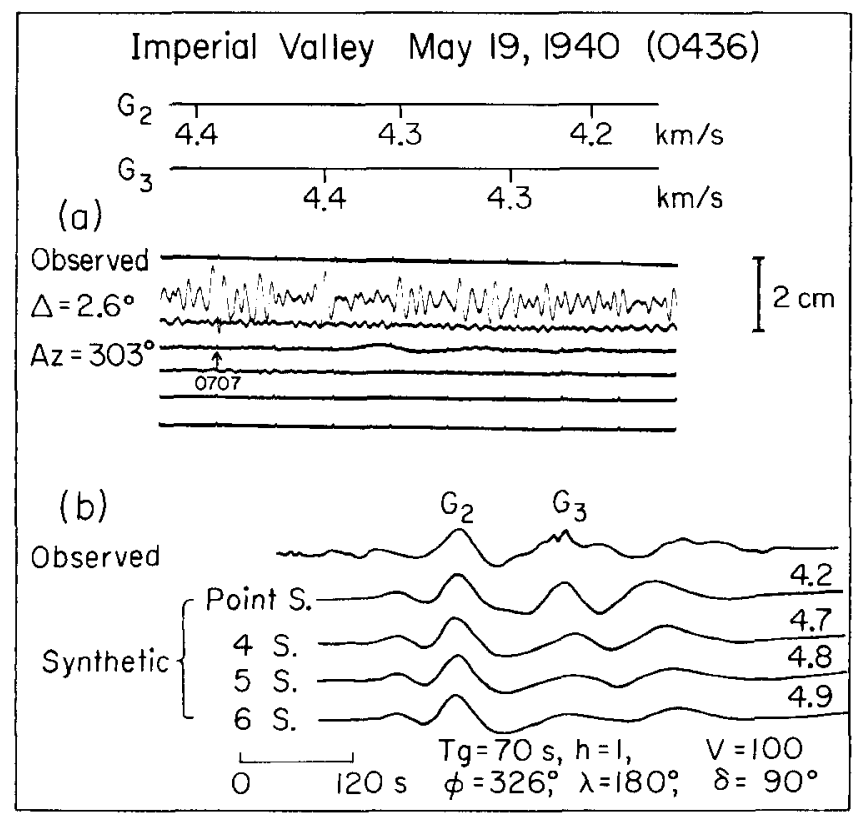

FIG. 4. Observed and synthetic seismograms for the Imperial Valley earthquake. The first synthetic is for a point source. The other synthetics model the earthquake as a series of 4 to 6 point sources spaced $17.5 \mathrm{~km}$ apart occurring $7 \mathrm{sec}$ apart in time. In this figure, the numbers above each seismogram denote the moment $\times 10^{19} \mathrm{~N}-\mathrm{m}$. $\lambda=$ rake; $\delta=$ dip.

(1984) matched vertical movements along the Imperial fault from 1931 to 1941 by treating the southern and northern parts of the Imperial fault independently. His best model had shallow slip ( 0 to $13 \mathrm{~km}$ depth) of $1.5 \mathrm{~m}$ along the northern $30 \mathrm{~km}$ of the fault and shallow slip of $4.5 \mathrm{~m}$ along the southern $35 \mathrm{~km}$ of the fault, with deeper slip (13 to $100 \mathrm{~km}$ depth) along the entire fault. If we consider the shallow slip to be predominantly an effect of the 1940 earthquake, we obtain a moment of $8.4 \times 10^{19} \mathrm{~N}-\mathrm{m}$ for the event. In comparison, the seismic moment from Rayleigh waves of 200 - to 250 -sec periods for the 1979 Imperial Valley earthquake, an event that occurred along the northern part of the Imperial Valley fault that ruptured in 1940 , is $7 \times 10^{18} \mathrm{~N}-\mathrm{m}$ (Kanamori and Regan, 1982).

\section{CONCLUSIONS}

We have modeled strainmeter seismograms recorded at Pasadena for four earthquakes that have been studied extensively by other researchers in order to determine the seismic moment at long periods. In most cases, the synthetic seismograms are not sensitive to changes of up to $\pm 30^{\circ}$ in strike, dip, and rake, or to changes in fault length. Estimates of moment from long-period surface waves agree well with moments estimated from geodetic data, but are 1.5 to 5 times larger than moments estimated from body waves or geologic information. Fault parameters estimated from surface wave modeling are also consistent with the geodetic data. This suggests that source parameters obtained from the modeling of long-period strainmeter records give good estimates of the long-term rupture process during an earthquake.

For the Hebgen Lake earthquake, it was possible to differentiate between two different fault models, but this may be a special case where the station was favorably oriented with respect to the focal mechanism. The modeling of the Imperial Valley earthquake suggests that it may also be possible to determine the rupture direction. 
Thus, strainmeter seismograms provide a useful addition to studies of large ( $M$ $>6.5$ ) earthquakes occurring before 1960 . They may be the only seismograms that can be used to provide moment and fault parameter information for earthquakes at epicentral distances less than $30^{\circ}$, although the resolution of fault parameters may be as poor as $\pm 30^{\circ}$. While modeling the surface waves of these four earthquakes, we have noted clear $P_{n l}$ arrivals for some of the earthquakes. It is possible that the $P_{n l}$ arrivals could be used to help constrain the surface wave estimates of fault parameters.

\section{ACKNOWLEDGMENTS}

This research was supported by U.S. Geological Survey Contract 14-08-0001-G1171. D. Doser was also supported by a Caltech Bantrell postdoctoral fellowship. Contribution no. 4294, Division of Geological and Planetary Science, California Institute of Technology, Pasadena, California 91125.

\section{REFERENCES}

Ben-Menahem, A. (1961). Radiation of seismic surface waves from finite moving sources, Bull. Seism. Soc. Am. 51, 401-435.

Benioff, H. (1935). A linear strain seismograph, Bull. Seism. Soc. Am. 25, 283-309.

Doser, D. I. (1985a). Source parameters and faulting processes of the 1959 Hebgen Lake, Montana, earthquake sequence, J. Geophys. Res. 90, 4537-4555.

Doser, D. I. (1985b). The 1954 Fallon-Fairview Peak-Dixie Valley, earthquakes: a complex sequence of fault ruptures in the western Great Basin (abstract), EOS 66, 964.

Doser, D. I. and H. Kanamori (1986). Depth of seismicity in the Imperial Valley-southern Peninsular Ranges region (1977-1983) and its relationship to heatflow, crustal structure, and the October 15, 1979 earthquake, $J$. Geophys. Res. 91, 675-688.

Kanamori, H. (1970). Velocity and $Q$ of mantle waves, Phys. Earth Planet. Interiors 2, 259-275.

Kanamori, H. and J. J. Cipar (1974). Focal process of the great Chile earthquake May 22, 1960, Phys. Earth Planet. Interiors 9, 128-136.

Kanamori, H. and G. S. Stewart (1979). A slow earthquake, Phys. Earth Planet. Interiors 18, 167-175.

Kanamori, H. and J. Regan (1982). Long-period surface waves, in the Imperial Valley California earthquake of October 15, 1979, U.S. Geol. Surv. Profess. Paper 1254, 55-58.

Okaya, D. A. and G. A. Thompson (1985). Geometry of Cenozoic extensional faulting: Dixie Valley, Nevada, Tectonics 4, 107-126.

Reilinger, R. (1984). Coseismic and post seismic vertical movements associated with the $1940 M 7.1$ Imperial Valley, California, earthquake, J. Geophys. Res. 89, 4531-4538.

Richter, C. F. (1958). Elementary Seismology, W. H. Freeman and Co., San Francisco, California.

Romney, C. (1957). Seismic waves from the Dixie Valley-Fairview Peak earthquakes, Bull. Seism. Soc. Am. 47, 301-319.

Ryall, A. (1962). The Hebgen Lake, Montana, earthquake of August 17, 1959, $P$-waves, Bull. Seism. Soc. Am. 52, 235-271.

Savage, J. C. and L. M. Hastie (1966). Surface deformation associated with dip-slip faulting, J. Geophys. Res. 71, 4897-4904.

Savage, J. C. and L. M. Hastie (1969). A dislocation model for the Fairview Peak, Nevada, earthquake, Bull. Seism. Soc. Am. 59, 1937-1948.

Sharp, R. V. (1982). Comparison of 1979 surface faulting with earlier displacements in the Imperial Valley, California, earthquake of October 15, 1979, U.S. Geol. Surv. Profess. Paper 1254, 213-221.

Slemmons, D. B. (1957). Geologic effects of the Dixie Valley-Fairview Peak Nevada earthquakes of December 16, 1954, Bull. Seism. Soc. Am. 47, 353-375.

Snay, R. A., M. W. Cline, and E. L. Timmerman (1985). Dislocation models for the 1954 earthquake sequence in Nevada, U.S. Geol. Surv., Open-File Rept. 85-290, 531-555.

Trifunac, M. D. and J. N. Brune (1970). Complexity of energy release during the Imperial Valley, California, earthquake of 1940, Bull. Seism. Soc. Am. 60, 137-160.

Witkind, I. J. (1964). Reactivated faults north of Hebgen Lake, U.S. Geol. Surv. Profess. Paper 435, 3750.

SEISMOLOGICAL LABORATORY

CAlifornia Institute of TeChNOLOgY

Pasadena, California 91125

Manuscript received 8 January 1986 